\title{
Thalamic haemorrhage vs internal capsule-basal ganglia haemorrhage: clinical profile and predictors of in-hospital mortality Adrià Arboix ${ }^{* 1}$, Raquel Rodríguez-Aguilar ${ }^{2}$, Montserrat Oliveres ${ }^{1}$, Emili Comes ${ }^{1}$, Luis García-Eroles ${ }^{3}$ and Joan Massons ${ }^{1}$
}

Address: ${ }^{1}$ Cerebrovascular Division, Department of Neurology, Hospital Universitari del Sagrat Cor, Universitat de Barcelona, Barcelona, Spain, ${ }^{2}$ Department of Internal Medicine, Hospital Universitari del Sagrat Cor, Universitat de Barcelona, Barcelona, Spain and ${ }^{3}$ Clinical Information Systems, Hospital Universitari de Bellvitge, L'Hospitalet de Llobregat, Barcelona, Spain

Email: Adrià Arboix* - aarboix@hscor.com; Raquel Rodríguez-Aguilar - rrodriguez@meditex.es; Montserrat Oliveres - 11466moi@comb.es; Emili Comes - ecomesm@meditex.es; Luis García-Eroles - Igarciaer@csdm.es; Joan Massons - jmassonsc@terra.es

* Corresponding author

Published: 5 October 2007

BMC Neurology 2007, 7:32 doi:10.1 186/147|-2377-7-32
Received: 8 June 2007

Accepted: 5 October 2007

This article is available from: http://www.biomedcentral.com/I47/-2377/7/32

(c) 2007 Arboix et al; licensee BioMed Central Ltd.

This is an Open Access article distributed under the terms of the Creative Commons Attribution License (http://creativecommons.org/licenses/by/2.0), which permits unrestricted use, distribution, and reproduction in any medium, provided the original work is properly cited.

\begin{abstract}
Background: There is a paucity of clinical studies focused specifically on intracerebral haemorrhages of subcortical topography, a subject matter of interest to clinicians involved in stroke management. This single centre, retrospective study was conducted with the following objectives: a) to describe the aetiological, clinical and prognostic characteristics of patients with thalamic haemorrhage as compared with that of patients with internal capsule-basal ganglia haemorrhage, and b) to identify predictors of in-hospital mortality in patients with thalamic haemorrhage.
\end{abstract}

Methods: Forty-seven patients with thalamic haemorrhage were included in the "Sagrat Cor Hospital of Barcelona Stroke Registry" during a period of 17 years. Data from stroke patients are entered in the stroke registry following a standardized protocol with $|6|$ items regarding demographics, risk factors, clinical features, laboratory and neuroimaging data, complications and outcome. The region of the intracranial haemorrhage was identified on computerized tomographic (CT) scans and/or magnetic resonance imaging (MRI) of the brain.

Results: Thalamic haemorrhage accounted for $1.4 \%$ of all cases of stroke $(n=3420)$ and $13 \%$ of intracerebral haemorrhage $(n=364)$. Hypertension $(53.2 \%)$, vascular malformations $(6.4 \%)$, haematological conditions (4.3\%) and anticoagulation (2.1\%) were the main causes of thalamic haemorrhage. In-hospital mortality was 19\% $(n=9)$. Sensory deficit, speech disturbances and lacunar syndrome were significantly associated with thalamic haemorrhage, whereas altered consciousness (odds ratio $[O R]=39.56)$, intraventricular involvement $(O R=24.74)$ and age $(O R$ $=1.23$ ), were independent predictors of in-hospital mortality.

Conclusion: One in 8 patients with acute intracerebral haemorrhage had a thalamic hematoma. Altered consciousness, intraventricular extension of the hematoma and advanced age were determinants of a poor early outcome. 


\section{Background}

Most studies of primary intracerebral haemorrhages are focused on the global assessment of patients with haemorrhagic stroke independent of the different topography of lesions $[1,2]$. It has recently been shown that the clinical spectrum, prognosis and early mortality of patients with primary intracerebral haemorrhage are reasonably dependent on the site of bleeding [3]. On the other hand, thalamic haemorrhages and basal ganglia-internal capsule haemorrhages are a group of supratentorial cerebral haemorrhages of subcortical topography, with clinical characteristics that are clearly different from those of the remaining cases of lobar or brainstem haemorrhages $[1,2]$. However, the differential clinical profile between subcortical cerebral haemorrhages of isolated thalamic topography and haemorrhages involving the basal ganglia and the internal capsule is poorly defined. Moreover, predictors of in-hospital mortality in patients with isolated thalamic haemorrhage are not clearly established probably because in clinical series collected from hospital-based stroke registries, separate analysis of thalamic haemorrhage as an individual clinical entity is rarely performed.

This aim of this study was to describe the aetiological, clinical and prognostic characteristics of patients with thalamic haemorrhage as compared with that of patients with basal ganglia-internal capsule haemorrhage collected from a prospective hospital-based stroke registry. A second objective was to identify predictors of in-hospital mortality in patients with thalamic haemorrhage.

\section{Methods}

The database of the "Sagrat Cor Hospital of Barcelona Stroke Registry" with data of 3420 acute stroke patients was searched for those with a diagnosis of intracerebral haemorrhage who were admitted consecutively to the Department of Neurology of the Sagrat Cor Hospital (an acute-care 350-bed teaching hospital in the city of Barcelona) between January 1986 and December 2002. Details of this on-going hospital-based stroke registry have been reported in previous studies [4,5]. Data from stroke patients are entered following a standardized protocol with 161 items regarding demographics, risk factors, clinical features, laboratory and neuroimaging data, complications and outcome. Subtypes of stroke were classified according to the Cerebrovascular Study Group of the Spanish Neurological Society [6], which is similar to the National Institute of Neurological Disorders and Stroke Classification [7]. Definitions of cerebrovascular risk factors have been used by our group in previous studies [35].

For the purpose of this study, primary intracerebral haemorrhages diagnosed in 364 patients were collected. The region of the intracranial haemorrhage was identified on computerized tomographic (CT) scans and/or magnetic resonance imaging (MRI) of the brain. The volume of haematomas was measured. Haematomas were divided into small and large using a diameter of $30 \mathrm{~mm}$. Topographies included the thalamus in 47 patients, internal capsule and basal ganglia in 77 , cerebral lobes in 140 , cerebellum in 27 , brainstem in 18 , primary intraventricular haemorrhage in 11 and multiple topographic involvement (when more than one of the aforementioned topographies was affected by the haemorrhage and the size of the haematoma was $>30 \mathrm{~mm}$ ) in 44 . The objective of this clinical study was to assess differential features in aetiology, risk factors, clinical findings and early outcome between the cohorts of patients with thalamic haemorrhage $(n=47)$ and internal capsule-basal ganglia haemorrhage $(n=77)$. Prior to conducting the study, approval was obtained from the Ethical Committee of Clinical Research of the hospital.

All patients were admitted to the hospital within 48 hours of onset of symptoms. On admission, demographic characteristics; salient features of clinical and neurological examination and results of laboratory tests (blood cell count, biochemical profile, serum electrolytes, urinalysis); chest radiography; twelve-lead electrocardiography; and brain CT and/or MRI were recorded. Angio-MRI was obtained during hospitalisation in $17 \%$ of cases and arterial digital subtraction angiography was performed in $16 \%$ of patients with thalamic haemorrhage in whom we could not find any risk factor for haemorrhagic stroke. Other investigations included echocardiography in 10.6\% of patients and lumbar puncture in $6.4 \%$. Degree of clinical disability at discharge from the hospital was evaluated according to modified Rankin scale (mRS) [8], and causes of death according to the criteria of Silver et al. [9].

\section{Statistical analysis}

Demographic characteristics, risk factors, clinical events and outcome of patients with thalamic haemorrhage and those with internal capsule-basal ganglia haemorrhage were compared using the Student's $t$-test or the MannWhitney $U$ test for continuous variables and the chisquare $\left(\chi^{2}\right)$ test (with Yate's correction when necessary) for categorical variables. Variables were subjected to multivariate analysis with a logistic regression procedure and forward stepwise selection if $P<0.10$ after univariate testing. The effect of variables on the presence of thalamic haemorrhage and fatal outcome was studied in two multiple regression models based on demographic, vascular risk factors, and clinical and neuroimaging variables, in which thalamic haemorrhage and in-hospital mortality were the dependent variables, respectively. Statistical significance was set at $P<0.05$. 


\section{Results}

Thalamic haemorrhage accounted for $1.4 \%$ of all cases of stroke $(n=3420)$ and $13 \%$ of intracerebral haemorrhage $(n=364)$. There were 27 men and 20 women with a mean (SD) age of 71.6 (10.9) years. The following vascular risk factors in a decreasing order of frequency were observed: history of hypertension (61.7\%), diabetes mellitus (17\%) and alcohol abuse (> $80 \mathrm{~g} /$ day) $(12.8 \%)$. Sudden onset of neurological deficit was recorded in $74.5 \%$ of cases. Motor deficit occurred in $78.7 \%$ of cases, sensory deficit in $70.2 \%$, altered consciousness in $31.9 \%$, headache in $29.8 \%$, nausea or vomiting in $27.7 \%$, speech disturbances (dysarthria, aphasia) in 21.3\% and oculomotor and visual disturbances in $21.3 \%$ (upward gaze palsy with miotic unreactive pupils, skew ocular deviation). Abnormal involuntary movements were present in only 2 patients. On the other hand, 4 patients had a lacunar syndrome (pure sensory stroke 3, sensorimotor stroke 1). The topography of thalamic lesion [10] was anterior in $6 \%$ of cases, posteromedial in $24 \%$, posterolateral in $48 \%$, dorsal in $2 \%$ and affected all thalamic vascular territories in $20 \%$. Intraventricular involvement was present in $42.6 \%$ of patients.

Hypertension (53.2\%), vascular anomaly (6.4\%), haematological conditions (4.3\%) and anticoagulation (2.1\%) were the main causes of thalamic haemorrhage. The aetiology of thalamic bleeding was not identified in 34\% of patients. One patient had surgical intervention (ventricular drainage). Median duration of hospital stay was 20 days (25th-75th percentile, 11-30 days). At the time of hospital discharge, 1 patient $(2.1 \%)$ was symptom free (mRS grade 0 ). Of the remaining 37 patients, 11 had moderate disability (mRS grade 3 ), 15 moderately severe disability (mRS grade 4) and 11 severe disability (mRS grade 5). Significant altered memory function was present in 1 patient at hospital discharge. A total of 9 patients died (in-hospital mortality rate 19.1\%). The median time of death was 11 days (25th-75th percentile, 6-13.5 days). Cumulative in-hospital mortality in relation to length of hospital stay showed that 33\% of all deaths had occurred on day $7,88.5 \%$ on day 14 , and $100 \%$ on day 90 . Causes of death included cerebral herniation in 4 patients, pneumonia in 2, sepsis in 2 and unknown cause in 1 .

When the groups of patients with thalamic haemorrhage with favourable and unfavourable outcome were compared (Table 1), advanced age, altered consciousness, neurological complications and intraventricular extension of the haemorrhage were significantly more frequent in patients who died. In the multivariate analysis, advanced age, altered consciousness and intraventricular involvement were independent variables significantly associated with in-hospital death (Table 2).
The characteristics of patients with thalamic haemorrhage in comparison with the cohort of 77 patients with internal capsule-basal ganglia haemorrhage are shown in Table 3. History of chronic liver disease, sensory symptoms, nausea and/or vomiting and ataxia was significantly more frequent in patients with thalamic haemorrhage, whereas speech disturbances (dysarthria, aphasia) and clinical presentation as a lacunar syndrome were significantly more common among patients with internal capsulebasal ganglia haemorrhage. In the multivariate analysis sensory deficit (odds ratio $[\mathrm{OR}]=2.33,95 \%$ confidence interval $[\mathrm{CI}] 1.10-4.84 ; P=0.040)$, speech disturbances (OR $=0.34,95 \%$ CI $0.16-0.86 ; P=0.015)$ and lacunar syndrome $(\mathrm{OR}=0.26,95 \% \mathrm{CI} 0.15-0.89 ; P=0.026)$ were independent predictors of isolated thalamic haemorrhage.

\section{Discussion}

Data regarding the frequency of isolated thalamic haemorrhage in the different hospital-based stroke registries are scarce, the present results show that thalamic haematomas is a subgroup of haemorrhagic stroke that accounted for $1.4 \%$ of all cases of stroke and $13 \%$ of intracerebral haemorrhages. The prevalence of thalamic haemorrhage in different series of primary intracerebral haemorrhage vary widely from $6 \%$ in the series of Juvela et al. [11] to $15.7 \%$ in the series of Tatu et al. [12]. In a subsample of 390 with haemorrhagic stroke reported by Kumral et al. [13], thalamic haemorrhage was diagnosed in 100 patients $(25.6 \%)$.

Results of the present study show that patients with thalamic haemorrhage and patients with internal capsulebasal ganglia haemorrhage presented different clinical profiles, with sensory disturbances being significantly more frequent and speech disorders and lacunar syndrome being significantly less frequent in patients with thalamic haematoma. Prominent sensory loss, either anaesthesia or hypaesthesia affecting face, limbs and trunk, generally for all sensory modalities was found in $70.2 \%$ of patients, which is consistent with classical reports showing the predominance of sensory deficit as a cardinal feature of thalamic haemorrhage especially when the ventroposterolateral nucleus is affected $[1,14,15]$.

Speech disturbances are less frequent in patients with thalamic haemorrhage $(21 \%)$ as compared with those with internal capsule-basal ganglia haemorrhage (44.2\%). Dysarthria and different types of aphasia was explained in thalamic haemorrhage as a disruption of any circuit (arranged as frontal rostrocaudal/thalamic mediolaterally) leading to dysfunction $[1,2]$. However, interruption of the corticolingual pathways in the internal capsule may explain the higher frequency of speech disturbances 
Table I: Results of univariate analysis in $\mathbf{4 7}$ patients with thalamic haemorrhage according to early outcome

\begin{tabular}{|c|c|c|c|}
\hline Data & Alive $(n=38)$ & Dead $(n=9)$ & $P$ value \\
\hline Age, years, mean (SD) & $69.5(10.9)$ & $80.2(5.2)$ & 0.002 \\
\hline \multicolumn{4}{|l|}{ Sex } \\
\hline Male & $24(88.9)$ & $3(11.1)$ & 0.106 \\
\hline Female & $14(70)$ & $6(30)$ & 0.371 \\
\hline \multicolumn{4}{|l|}{ Valvular heart disease } \\
\hline Absent & $38(100)$ & $8(17.4)$ & 0.191 \\
\hline Present & 0 & I (100) & \\
\hline \multicolumn{4}{|c|}{ Transient ischaemic attack } \\
\hline Absent & $38(100)$ & $8(17.4)$ & 0.191 \\
\hline Present & 0 & $\mathrm{I}(100)$ & \\
\hline \multicolumn{4}{|l|}{ Obesity } \\
\hline Absent & $36(83.7)$ & $7(16.7)$ & 0.160 \\
\hline Present & $2(50)$ & I (50) & \\
\hline \multicolumn{4}{|l|}{ Hyperlipidemia } \\
\hline Absent & $34(85)$ & $6(15)$ & 0.117 \\
\hline Present & $4(57.1)$ & $3(42.9)$ & \\
\hline \multicolumn{4}{|l|}{ Nausea, vomiting } \\
\hline Absent & $29(85.3)$ & $5(14.7)$ & 0.198 \\
\hline Present & $9(69.2)$ & $4(30.8)$ & \\
\hline \multicolumn{4}{|l|}{ Altered consciousness } \\
\hline Absent & $30(93.8)$ & $2(6.3)$ & 0.002 \\
\hline Present & $8(53.3)$ & 7 (46.7) & \\
\hline \multicolumn{4}{|l|}{ Sensory deficit } \\
\hline Absent & $9(64.3)$ & $5(35.7)$ & 0.074 \\
\hline Present & $29(87.9)$ & $4(12.1)$ & \\
\hline \multicolumn{4}{|l|}{ Lacunar syndrome } \\
\hline Absent & $34(79.1)$ & $9(20.9)$ & 0.724 \\
\hline Present & $4(100)$ & 0 & \\
\hline \multicolumn{4}{|c|}{ Intraventricular involvement } \\
\hline Absent & $26(96.3)$ & I (3.7) & 0.003 \\
\hline Present & $12(60)$ & $8(40.5)$ & \\
\hline \multicolumn{4}{|c|}{ Neurological complications } \\
\hline Absent & $36(90)$ & $4(10)$ & 0.001 \\
\hline Present & $2(28.6)$ & $5(71.4)$ & \\
\hline \multicolumn{4}{|l|}{ Respiratory events } \\
\hline Absent & $33(84.6)$ & $6(15.4)$ & 0.167 \\
\hline Present & $5(62.5)$ & $3(37.5)$ & \\
\hline
\end{tabular}

Data are $n(\%)$ unless otherwise stated.

Table 2: Variables associated with in-hospital death in patients with thalamic haemorrhage

\begin{tabular}{|c|c|c|c|c|}
\hline Variable & $\beta$ & SE $(\beta)$ & Odds ratio $(95 \% \mathrm{Cl})$ & $p$ \\
\hline \multicolumn{5}{|c|}{ Model based on demographics, vascular risk factors and clinical variables* } \\
\hline Altered consciousness & 3.223 & 1.120 & $25.10(2.8-225.3)$ & 0.004 \\
\hline Age & 0.160 & 0.069 & $1.17(1.03-1.34)$ & 0.020 \\
\hline \multicolumn{5}{|c|}{ Model based on demographics, vascular risk factors, clinical features and neuroimaging variables ${ }^{\dagger}$} \\
\hline Altered consciousness & 3.678 & 1.471 & $39.59(2.5 \mathrm{I}-707.37)$ & 0.012 \\
\hline Intraventricular involvement & 3.209 & 1.600 & $24.74(1.07-569.60)$ & 0.045 \\
\hline Age & 0.210 & 0.103 & $1.23(1.01-1.5 \mathrm{I})$ & 0.042 \\
\hline
\end{tabular}

$* \beta=-15.114$; SE $(\beta)=5.651$; goodness-of-fit $\chi^{2}=1.265 ; d f=7 ; P=0.989 ;$ area under the ROC curve $=0.924$; sensitivity $60 \%$; specificity $71 \%$; positive predictive value $56 \%$; negative predictive value $74 \%$; correct classification $66.9 \%$.

$\dagger \beta=-21.386 ;$ SE $(\beta)=9.304$; goodness-of-fit $\chi^{2}=1.604 ; \mathrm{df}=7 ; P=0.978$; area under the ROC curve $=0.949$; sensitivity $78 \%$; specificity $87 \%$; positive predictive value $57 \%$; negative predictive value $94 \%$; correct classification $85.1 \%$. 
Table 3: Differences between patients with thalamic haemorrhage and patients with internal capsule-basal ganglia haemorrhage

\begin{tabular}{|c|c|c|c|}
\hline Data & Thalamic haemorrhage & Internal capsule-basal ganglia haemorrhage & $P$ value \\
\hline Total patients & 47 & 77 & \\
\hline Sex, male & $27(57.4)$ & $50(64.9)$ & 0.259 \\
\hline Age, years, mean (SD) & $71.6(10.9)$ & $72.2(12.2)$ & 0.661 \\
\hline \multicolumn{4}{|l|}{ Vascular risk factors } \\
\hline Hypertension & $29(6 \mid .7)$ & $57(74)$ & 0.107 \\
\hline Diabetes mellitus & $8(17)$ & $9(11.7)$ & 0.282 \\
\hline Dyslipemia & $7(14.9)$ & $10(13)$ & $0.48 I$ \\
\hline Atrial fibrillation & $5(10.6)$ & II (I4.3) & 0.384 \\
\hline Ischaemic heart disease & $3(6.4)$ & $5(6.5)$ & 0.646 \\
\hline Cigarette smoking (> 20/day) & $3(6.4)$ & $8(10.4)$ & 0.339 \\
\hline Chronic liver disease & $5(10.6)$ & 0 & 0.007 \\
\hline \multicolumn{4}{|l|}{ Clinical findings } \\
\hline Sudden onset (min) & $35(74.5)$ & $48(52.3)$ & 0.115 \\
\hline Limb weakness & 37 (78.7) & $67(87)$ & 0.167 \\
\hline Sensory symptoms & $33(70.2)$ & $38(49.4)$ & 0.018 \\
\hline Altered consciousness & $15(31.9)$ & $23(29.9)$ & 0.482 \\
\hline Headache & $14(29.8)$ & $18(23.4)$ & 0.279 \\
\hline Nausea, vomiting & $13(27.7)$ & $10(13)$ & 0.037 \\
\hline Speech disturbances (dysarthria, aphasia) & $10(21.3)$ & $34(44.2)$ & 0.008 \\
\hline Ataxia & $4(8.5)$ & 0 & 0.019 \\
\hline Lacunar syndrome & $4(8.5)$ & $18(23.4)$ & 0.036 \\
\hline Ventricular involvement & $20(42.6)$ & $12(15.6)$ & 0.001 \\
\hline \multicolumn{4}{|l|}{ Outcome } \\
\hline In-hospital mortality & $9(19.1)$ & $13(16.9)$ & 0.464 \\
\hline Respiratory complications & $8(17)$ & $8(10.4)$ & 0.212 \\
\hline Urinary complications & $8(17)$ & $7(9.1)$ & 0.152 \\
\hline Infectious complications & $16(34)$ & $17(22.1)$ & 0.106 \\
\hline Symptom-free at discharge & $I(2.1)$ & $6(7.8)$ & 0.180 \\
\hline
\end{tabular}

Data are $n(\%)$ unless otherwise stated.

(mainly dysarthria) in internal capsule-basal ganglia haemorrhages $[16,17]$.

Clinical presentation of thalamic haemorrhage in the form of a lacunar syndrome is very rare, and was documented in only 4 patients $(8.5 \%), 3$ of whom presenting with a pure sensory stroke and 1 a sensorimotor syndrome. This finding is in accordance with a recent study of our group [18] and with data reported in the literature showing that pure sensory stroke is classically associated with a lacunar thalamic infarction [19].

Whereas none of the patients in the series of Kumral et al. [13] presented with pure sensorimotor stroke, a lacunar syndrome was observed in $23.4 \%$ of our patients with internal capsule-basal ganglia haemorrhage, mainly in the form of a pure motor stroke or sensorimotor stroke. These findings are consistent with the study of Weisberg and Wall (20) who reported pure motor hemiparesis in 7 out of 10 patients as well as with other reports indicating that a small haematoma of subcortical topography in the internal capsule but also in the basal ganglia may cause a lacunar syndrome [21].
Thalamic haemorrhage is a severe clinical condition with an in-hospital mortality rate, in the present study, of 19\%, and only one patient $(2.1 \%)$ was symptom-free at discharge. The mortality rate of thalamic haemorrhage was $12 \%$ after $6 \pm 6$ days after stroke and $17.3 \%$ within 6 months in the series of Mori et al. [22]. In the series of Chung et al. [23], the case fatality was $37 \%$ at the time of discharge. On the other hand, the mortality rate of thalamic haemorrhage is generally lower than that of brainstem haemorrhages or cerebral haemorrhages of multiple topographies, which show a very high in-hospital mortality rate usually greater than $40 \%$ [3]. The mortality rate in patients with thalamic haemorrhage, however, is higher than that of patient with capsular stroke $[3,16,17]$. Altered consciousness, intraventricular hemorrhage and advanced age were independent predictors of in-hospital mortality in patients with thalamic haematoma.

The initial level of consciousness was always found to be a predictor of mortality in the differents series [3,11-15]. Previous studies reported that initially comatose or stupurous patients had the poorest chance of survival $[1,2]$. Intraventricular haemorrhage has been found to be a pre- 
Table 4: Thalamic haemorrhage. Series reported in the literature

\begin{tabular}{|c|c|c|c|c|c|c|}
\hline Author, year [reference] & Patients & Type of study & $\begin{array}{l}\text { Frequency intracerebral } \\
\text { haemorrhages (\%) }\end{array}$ & $\begin{array}{l}\text { Ventricular } \\
\text { Extension (\%) }\end{array}$ & $\begin{array}{c}\text { Ventricular extension as } \\
\text { predictor of in-hospital death }\end{array}$ & $\begin{array}{l}\text { In-hospital } \\
\text { mortality (\%) }\end{array}$ \\
\hline Walshe, 1977 [14] & 18 & Clinical series & & 66 & & \\
\hline Barraquer-Bordas, 198I [15] & 23 & Clinical series & & 50 & & 39 \\
\hline Kwak, I $983[26]$ & 29 & Clinical series & & & No & \\
\hline Weisberg, 1986 [24] & 50 & Clinical series & & 38 & Yes & 38 \\
\hline Steinke, $1992[25]$ & 44 & Stroke data bank & & 47.7 & Yes & 31.8 \\
\hline Kumral, 1995 [13] & 100 & Stroke data bank & 25.6 & 57 & Yes & 25 \\
\hline Mori, I995 [22] & 104 & Clinical series & & 44 & No & I7.3 (6 months) \\
\hline Lampl, I995 [27]* & 52 & Clinical series & & 63.5 & No & 36.6 (6 moths) \\
\hline Chung, 1996 [23] & 175 & Clinical series & & & $\dagger$ & 37 \\
\hline Shah, 2005 [30] & 53 & Clinical series & & 66.6 & No & 15.7 \\
\hline Present series, 2007 & 47 & Hospital-based stroke registry & 13 & 42.6 & Yes & 19.1 \\
\hline
\end{tabular}

* I I patients with thalamo-capsular haemorrhages and $4 \mathrm{I}$ patients with isolated thalamic haemorrhages

tPresence of dense blood clot in the third ventricle in a CT scan indicate a poor outcome

dictor of in-hospital mortality in some studies [13,24,25] but not in others $[11,22,26]$ and one study has even suggested that intraventricular bleeding is associated with improved outcome in thalamic haemorrhage [27]. However, our results shows that stroke-related deaths occurred in $40.5 \%$ of intraventricular haemorrhage cases and agree with that of the Steinke et al. [25] who found that in-hospital mortality occurred in 52\% of thalamic haematomas with ventricular extension and that intraventricular extension is an powerful independent predictor of mortality (Table 4). Death increased with age and agree with the study of Mori et al. [22]. In the study of Daverat el al. [28], age was the most important predictor of death and functional outcome after spontaneous intracerebral haemorrhage.

Early expansion of cerebral haematoma of any topography is an important determinant of in-hospital mortality $[29,30]$. Recent studies have shown that ultra-early haemostatic therapy with recombinant activated factor VII (rFVIIa) within four hours after the onset of intracerebral hemorrhage limits the growth of the haematoma, reduces mortality, and improves functional outcomes [31]. These preliminary findings will probably determine a change in the management of patients with acute intracerebral haemorrhage, in which ultra-early haemostatic therapy, similar to the efficacy of early thrombolytic therapy in cerebral infarction -, followed by careful monitorization in specialised stroke units could be of paramount importance in the care of patients with intracerebral haemorrhage [32].

\section{Conclusion}

Approximately one in every 8 patients with acute intracerebral haemorrhage had a thalamic haematoma. Patients with isolated thalamic haemorrhage show a differential clinical profile than patients with internal capsule-basal ganglia haemorrhage. Altered consciousness, intraventricular involvement and advanced age were independent predictors of in-hospital mortality.

\section{Abbreviations}

CI: Confidence interval.

\section{CT: Computed tomography}

MRI: Magnetic resonance imaging

OR: Odds ratio.

ROC: Receiver operating characteristics.

SE: Standard error.

\section{Competing interests}

The author(s) declare that they have no competing interests.

\section{Authors' contributions}

AA was the principal investigator, chief of the Cerebrovascular Division, designed the study, diagnosed and took care of the patients, contributed to analyze the data, interpreted the results, wrote the paper, and prepared the final draft. He was also responsible for editorial decisions including the selection of the journal.

RR participated in the collection of data, search and review of the literature, analysis of results, review of the manuscript, and approved the final draft.

LG-E was the statistician, participated in the study design, analysis and interpretation of data, wrote the part of the paper related to the statistical analysis, and approved the final draft. 
EC, JM, and MO diagnosed and took care $\mathrm{f}$ the patients, contributed in the review of the literature, interpretation of the results, review of the paper for intellectual content, and approved the final draft.

\section{Acknowledgements}

We thank Drs O. García-Trallero, M. López, C. Manzano, M. Miguel and E. Císcar for their contribution in the collection of data, C. Targa and M. Balcells for the care of many of the patients included in the study, and Dr Marta Pulido for editing the manuscript and editorial assistance. No funding was received for the study itself or for editorial assistance.

\section{References}

I. Kase CS, Mohr JP, Caplan LR: Intracerebral hemorrhage. In Stroke. Pathophysiology, Diagnosis, and Management Edited by: Mohr JP, Choi DW, Grotta JC, Weir B, Wolf PhA. Philadelphia: Churchill Livingstone; 2004:327-376.

2. Kase CS: Subcortical hemorrhages. In Subcortical Stroke 2nd edition. Edited by: Donnan G, Norrving B, Bamford J, Bogousslavsky J. London, UK: Oxford University Press; 2002:347-377.

3. Arboix A, Comes E, García Eroles L, Massons J, Oliveres M, Balcells $M$, Targa C: Site of bleeding and early outcome in primary intracerebral hemorrhage. Acta Neurol Scand 2002, 105:282-288.

4. Arboix A, Morcillo C, García-eroles L, Massons J, Oliveres M, targa C: Different vascular risk factor profiles in ischemic stroke subtypes. The Sagrat Cor Hospital of Barcelona Stroke Registry. Acta Neurol Scand 2000, 102:264-270.

5. Arboix A, Massons J, García-eroles L, Oliveres M, Balcells M, Targa C: Migrainous cerebral infarction in the Sagrat-Cor Hospital of Barcelona Stroke Registry. Cephalalgia 2003, 23:389-394.

6. Arboix A, Alvarez-Sabín J, Soler L, for the Cerebrovascular Study Group of the Spanish Society of Neurology: Nomenclatura de las enfermedades vasculares cerebrales. Neurologia 1998 , I3(Suppl I): I- I0.

7. Special Report from the National Institute of Neurological Disorders and Stroke: Classification of cerebrovascular diseases. III. Stroke 1997, 28:1590-1594.

8. Bamford JM, Sandercock PAG, Warlow CP, Slattery J: Interobserver agreement for the assessment of handicap in stroke patients. Stroke 1989, 20:828.

9. Silver FL, Norris JW, Lewis Al, Hachinski VC: Early mortality following stroke: a prospective review. Stroke 1984, 15:492-496.

10. Schmahmann JD: Vascular syndromes of the thalamus. Stroke 2003, 34:2264-2278

II. Juvela S: Risk factors for impaired outcome after spontaneous intracerebral hemorrhage. Arch Neurol 1995, 52: I | 93- I 200.

12. Tatu L, Moulin Th, Mohamad RE, Vuillier F, Rumbach L, Czorny A: Primary intracerebral hemorrhages in the Besançon Stroke Registry. Initial clinical and CT findings, early course and 30day outcome in 350 patients. Eur Neurol 2000, 43:209-2I4.

13. Kumral E, Kocaer T, Ertubey NO, Kumral K: Thalamic hemorrhage. A prospective study of 100 patients. Stroke 1995, 26:964-970

14. Walshe TM, Davis KR, Fisher CM: Thalamic hemorrhage: a computed tomographic-clinical correlation. Neurology 1977, 27:217-222

15. Barraquer-Bordas L, Illa I, Escartín A, Ruscalleda J, Martí-Vilalta JL: Thalamic hemorrhage. A study of 23 patients with diagnosis by computed tomography. Stroke 1981, I 2:524-527.

16. Arboix A, Martínez-Rebollar M, Oliveres M, García-Eroles L, Massons J, Targa C: Acute isolated capsular stroke: a clinical study of 148 cases. Clin Neurol Neurosurg 2005, 107:88-94.

17. Miyai I, Suzuki T, Kang J, Volpe BT: Functional outcome in patients with hemorrhagic stroke in putamen and thalamus compared with those with stroke restricted to the putamen or thalamus. Stroke 2000, 31:1365-1369.

18. Arboix A, García-Plata C, García-Eroles L, Massons J, Comes E, Oliveres $\mathrm{M}$, Targa C: Clinical study of $\mathbf{9 9}$ patients with pure sensory stroke. I Neurol 2005, 252: 156-162.

19. Fisher CM: Lacunar infarcts. A review. Cerebrovasc Dis 1991, I:3 I I-320.
20. Weisberg LA, Wall M: Small capsular hemorrhages: clinicalcomputed correlations. Arch Neurol I984, 4 I: |255-I257.

21. Milandre L, Donnet A, Graziani N, Grisoli F, Khalil R: Les syndromes lacunaires par hémorragie intracérébrale. Acta Neurol Belg 1992, 92: 125-137.

22. Mori S, Sadoshima S, Ibayashi S, Fujishima M: Impact of thalamic hematoma on six-month mortality and motor and cognitive outcome. Stroke 1995, 26:620-626.

23. Chung CS, Caplan LR, Han W, Pessin MS, Lee KH, Kim JM: Thalamic hemorrhage. Brain 1996, I 19:1873-1886.

24. Weisberg LA: Thalamic hemorrhage: clinical-CT correlations. Neurology 1986, 36:1382-1386.

25. Steinke W, Sacco RL, Mohr JP, Foulkes MA, Tatemichi TK, Wolf PA, Price TR, Hier DB: Thalamic stroke. Presentation and prognosis of infarcts and hemorrhages. Arch Neurol 1992, 49:703-7I0.

26. Kwak R, Kadoya S, Suzuki T: Factors affecting the prognosis in thalamic hemorrhage. Stroke 1983, I 4:493-500.

27. Lampl Y, Gilad R, Eshel Y, Sarova-Pinhas I: Neurological and functional outcome in patients with supratentorial hemorrhages. Stroke 1995, 26:2249-2253.

28. Daverat P, Castel JP, Dartigues JF, Orgogozo JM: Death and functional outcome after spontaneous intracerebral hemorrhage: a prospective study of 166 cases using multivariate analysis. Stroke I99I, 22: I-6.

29. Brott T, Broderick J, Kothari R, Barsan W, Tomsick T, Sauerbeck L, Spilker J, Duldner J, Khoury J: Early hemorrhage growth in patients with intracerebral hemorrhage. Stroke 1997, 28: I-5.

30. Shah SD, Kalita J, Misra UK, Mandal SK, Srivastava M: Prognostic predictors of thalamic hemorrhage. J Clin Neurosci 2005, 1 2:559-561.

31. Mayer SA, Brun NC, Begtrup K, Broderick J, Davis S, Diringer MN Skolnick BE, Steiner T, for the Recombinant Activated Factor VII Intracerebral Hemorrhage Trial Investigators: Recombinant activated factor VII for acute intracerebral hemorrhage. N Engl J Med 2005, 352:777-785

32. Dávalos A: New perspectives in cerebral hemorrhage: from surgery to conservative treatment. [Article in Spanish]. Med Clin (Barc) 2005, 124:735-736.

\section{Pre-publication history}

The pre-publication history for this paper can be accessed here:

\section{http://www.biomedcentral.com/1471-2377/7/32/prepub}

Publish with Bio Med Central and every scientist can read your work free of charge

"BioMed Central will be the most significant development for disseminating the results of biomedical research in our lifetime. "

Sir Paul Nurse, Cancer Research UK

Your research papers will be:

- available free of charge to the entire biomedical community

- peer reviewed and published immediately upon acceptance

- cited in PubMed and archived on PubMed Central

- yours - you keep the copyright
BioMedcentral 